\title{
Artigo
}

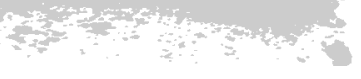

\section{Nação, Região, Cidadania: A Construção das Cozinhas Regionais no Projeto Nacional Brasileiro}

Rogéria Campos de Almeida Dutra

UFJF
"Somos um capítulo da história das utopias européias". Assim Otávio Paz (Velloso 1988:240) resume a situação colonial americana, que marca definitivamente o processo de construção do Brasil como nação. Afinal, a condição histórica deste território já fazia parte, em sua origem, de um fluxo hegemônico de projetos e decisões europeus. Podemos identificar na história brasileira uma relação constantemente ambígua desta realidade des-locada e todo o esforço em trazer para si o eixo de auto-definição, seja no sentido da constituição do Estado brasileiro, a organização da sociedade politicamente independente neste território; seja no processo de construção da identidade nacional.

Fundamental neste processo é verificar o modo como se consolidou a noção de unidade, de poder centralizador, de homogeneidade interna e continuidade simbólica, a partir de uma noção de cultura nacional, e a atuação dos espaços regionais, com interesses específicos e expressões particulares.

A conquista de uma "unidade moralmente homogênea e integrada", nos termos de Mauss (1972), supõe a comunhão de valores essenciais, definidores de um modo de ser, a partir dos quais se é reconhecido. Contudo, sabemos que este "compartilhar", mais que um dado real, é construído, elegendo-se traços significativos, relevantes à própria imagem que um grupo constrói para si e para os outros. Para tal fim, observam-se diversas estratégias, negociações, envolvendo a participação de diferentes atores sociais No processo de construção da identidade nacional, no caso brasileiro, destaca-se fortemente o fenômeno de apropriação de manifestações culturais específicas a certos grupos sociais por parte do resto da sociedade, e sua transformação em símbolos nacionais. Em diferentes Campos 5(1):93-110, 2004. momentos, observamos variadas contribuições que circulam entre a cultura 
popular e a erudita; e a cada momento, um tipo social faz-se seu portador legítimo, ou representativo. Como exemplos clássicos desta apropriação e sua reelaboração cultural, pode-se destacar o samba, o candomblé, a umbanda e a própria feijoada, quando as elites, num certo período da história brasileira, se apropriam e reelaboram estas manifestações, então restritas às camadas populares, como símbolo da nação. (Fry 1982; Oliven 1983, Viana 1995)

Contudo, se há emblemas que se pretendem superadores de certa incomensurabilidade, interligando grupos sociais diversos, ocorre também a construção desta identidade pela composição do diverso, que não se dilui no todo. Este, ao que parece, é o percurso simbólico próprio da composição do nacional a partir das diversas regiões que compõem seu território, princípio este embutido na própria representação do federalismo, emblematizado na forma de constelação em nossa bandeira. A construção deste mosaico se dá por diversas formas, a partir de inúmeros atributos regionais. Dentre estes, podemos identificar as cozinhas regionais, que funcionam como operadores distintivos que qualificam a riqueza nacional. Interessa-me particularmente a construção da singularidade regional a partir deste complexo de alimentos específicos, seus usos e combinações que, ao que parece, destaca-se como portadoras da identidade local mais em algumas regiões do que em outras. O propósito deste texto é analisar a construção da cozinha regional na formação da identidade nacional, o que torna indispensável pensarmos o diálogo histórico entre a unidade territorial e a diversidade regional na construção do Estado Brasileiro.

\section{A NAÇÃO COMO ESTADO}

Foram circunstâncias originais que delinearam o espaço geográfico do Brasil colonial, que se definia como "realidade aterritorial, sul atlântica"(Alencastro 2000) de forma marcadamente distinta do espaço nacional contemporâneo. Apesar de abrigar-se sob o nome de Terra de Santa Cruz, o território caracterizava-se por sua composição pluridimensional. Enquanto a costa Leste-Oeste (do Amazonas ao Ceará) permanece incomunicável ao litoral já povoado, denunciando uma distância já estruturalmente orientada, Angola se manifesta tão fortemente presente que se faz próxima e agregada. As razões desta contextualização referemse às condições adversas de navegação na direção norte via Atlântico - fatores tais como o sistema de ventos e correntes marítimas - e ao intenso comércio negreiro com o continente africano, comércio este vital à sobrevivência da nova colônia: impossível pensar o Brasil colônia dissociado de seu par complementar, as colônias portuguesas na África; o Brasil inserindo-se no cenário mundial à base da produção escravista e Angola pela reprodução de escravos. 
A manutenção da unidade política marca a diferença entre os processos de independência das colônias espanholas e portuguesa na América. Não tivemos aqui uma mudança de governo traumática, seja violenta, seja popular, conservando-se a supremacia do governo civil. Mais que expressão da vontade popular, o fim do período colonial resulta de uma disputa no âmbito do poder metropolitano, gerando a organização na forma de Império constitucional. A vinda da coroa portuguesa para o Rio de Janeiro, a elevação da colônia à qualidade de vice-reino possibilitou a adoção de uma solução monárquica a esta transição, com a manutenção da unidade, ainda que precária, da ex-colônia. As possibilidades de separatismo foram neutralizadas, também, pela presença de uma elite política ideologicamente homogênea, não só por sua formação jurídica em Portugal, quanto pelo treinamento no funcionalismo público (Carvalho 1996). Nos termos de Faoro (1975), a história da sociedade brasileira é permeada, desde seus primórdios, pela presença de um estamento burocrático, ou seja, um grupo instalado no núcleo decisório do Estado, que se caracteriza pela autonomia e uma certa permanência frente à alternância de grupos dominantes no poder.

O governo central se afirma enquanto autoridade legítima na medida em que representa e defende, no plano internacional, os interesses da elite agrária na manutenção do tráfico negreiro. A integração territorial ainda é incipiente, fruto do acordo entre diferentes regiões sob a tutela da burocracia imperial. As rebeliões regenciais são testemunho das dificuldades de se estabelecer um sistema nacional de dominação, dado o caráter ambíguo desta nova sociedade: escravocrata, com instituições representativas; agrária e analfabeta, com uma elite cosmopolita (Carvalho 1996). Enquanto o elemento popular confina-se a questões locais e regionais, em estado de dependência absoluta de proprietários rurais e sem condição de ação no âmbito nacional, a administração pública, através da burocracia imperial, empenha-se na modernização do país, na transformação da sociedade através do aparelho estatal. Uma burocracia que qualifica o Estado simultaneamente como onipotente - capaz de decidir grandes questões, como a escravidão ou a imigração - mas incapaz de se fazer presente no âmbito das municipalidades e das províncias.

É em torno da figura de Pedro II que em muito se personificou a unidade do Estado nacional, assim como a responsabilidade de introdução da "modernidade" no país, o projeto iluminista de integrar o Brasil à cultura ocidental, ao mundo civilizado. No entanto, o Brasil imperial ainda apresenta uma precária integração territorial. Estrategicamente, controlava-se a possibilidade de maior aquisição de poder por parte das províncias - de forma a manter o governo centralizado - ao se escolher cuidadosamente os presidentes das províncias fora dos quadros da elite provincial, evitando-se assim associá-los com os interesses regionais.

O jogo entre a pacificação interna e a belicosidade externa como fator de consolidação da legitimidade da autoridade central, narrada por Elias (1993) no processo de consolidação do Estado moderno, se faz nítido 
no caso brasileiro durante a Guerra do Paraguai. Vencidas as rebelióes provinciais, o confronto com o inimigo externo atua como grande estímulo à formação do sentimento de nação. Neste momento, a necessidade da busca de um espírito novo para o país já vinha sendo tematizada na literatura, através do romantismo, espelhando-se nos acontecimentos no campo europeu. Comprometida com a consolidação da própria singularidade enquanto nação, a literatura romântica vem expressar o anseio de liberdade, autonomia política e individuação nacional. Mesmo que para este fim fosse necessário transfigurar uma realidade mal conhecida, produzindo heróis acobreados, imbatíveis, representantes de nossa ancestralidade ameríndia.

À nula participação popular na proclamação da República, seguem-se tentativas de legitimação deste novo regime. Os esforços foram vários, no sentido de incluir a população na autoria deste novo projeto político, através de uma "batalha de símbolos e alegorias" (Carvalho 1990) que almejavam a redefinição dos ideais coletivos. No entanto, e em termos gerais, as diversas correntes republicanas falharam ao tentar expandir a legitimidade do novo regime, ineficazes que foram na criação de um imaginário republicano e no estímulo a um sentido de participação a vastos setores da população. Triunfa a elite política dos grandes estados - São Paulo, Minas Gerais e Rio Grande do Sul - e instaura-se a república oligárquica, ou seja, de uns poucos. Através do modelo federativo, concretiza-se o anseio de autonomia estadual, já reivindicado nos tempos imperiais (principalmente por parte destes estados que já apresentavam maior organização econômica) fazendose legítimos os interesses de cada região. A idéia e a experiência política do modelo federalista inaugura um novo horizonte de negociações no âmbito da administração central sob o princípio de relações de igualdade e liberdade de atuação.

Contudo, se o Estado brasileiro já apresentava uma unidade política, permanecia ausente o sentimento nacional. Cabe à geração intelectual da Primeira República, particularmente ao Movimento Modernista, a busca de uma identidade coletiva para o país - embora a geração romântica já tivesse iniciado este processo -, empenhando-se no exercício de reconhecimento do laço, antes que jurídico, afetivo. O modernismo denuncia, sobretudo, nossa crise identitária, assinalada pelo divórcio entre cultura e realidade, ou entre cultura erudita e cultura popular. Ao criticar o formalismo da cultura de então, seu caráter bacharelesco, ele propõe o rompimento com a "sociabilidade artificial" da sociedade imperial e escravocrata inspirada na aristocracia européia. Propõese à redescoberta do Brasil, inserindo-se a participação dos grupos populares como componentes da nação. É preciso fundar na cultura nacional o registro de uma temporalidade própria, o que não significa romper com o passado em busca do "moderno". Ao contrário, é preciso incluí-lo. A possibilidade de se ingressar na civilização, de se universalizar, é exatamente mergulhar nas próprias raízes. $\mathrm{O}$ atraso do tempo nacional passa a ser nossa própria temporalidade; o descompasso cultural, nossa própria riqueza. 
Se o modernismo propõe à sociedade brasileira sua reatualização através de um projeto estético, a Revolução de 30 endossa-o numa perspectiva ideológica. A partir da retomada da centralização do poder, o Estado brasileiro assume para si a tarefa de fundar a modernização no país, consolidando e viabilizando um novo tipo de nacionalismo. O mercado nacional se territorializa na medida em que o fluxo de africanos e imigrantes se interrompe. O Estado deixa de intervir na captação de proletários estrangeiros para cuidar do enquadramento do proletariado nacional, inaugurando uma nova fase de conexões entre população e regiões. Há de se relevar, como bem se refere Alencastro (1987), que enquanto o mercado de trabalho se alimentava do tráfico negreiro e da imigração, o discurso ideológico resumia-se ao diálogo "intra-elites", entre classes dirigentes - a burocracia imperial e a republicana - e as classes dominantes, representadas pelas oligarquias regionais. Na medida em que a força de trabalho se territorializa, o discurso ideológico se refaz frente à necessidade de se unir dominantes e dominados; seja através do patriarcalismo, seja via nacionalismo. Nunca se revelou tão nitidamente o desajuste entre sociedade e Estado e a necessidade de superá-lo. No lugar do setor agro-exportador, o governo pós-30 apóia-se no eixo urbano-industrial buscando um ponto de equilíbrio entre o sistema democrático - através de valores universais e racionais - e manifestações de espontaneidade nacional. Através da educação, objetiva-se a formação de cidadãos conscientes, de forma a possibilitar o alargamento da participação política. Assistimos então a um movimento de unificação cultural, projetando na escala nacional fatos que ocorriam no âmbito das regiões. Exemplo claro desta tendência está na literatura, que se pretende, de forma mais acentuada, representar, atuar como "espelho da nação" (Velloso 1989). Ao se construir como reflexo fiel da realidade, ela reforça sua tradição documental. A literatura regional expressa de modo significativo este exercício. Neste momento não mais "regionalista pitoresca", aquela que colore a realidade diversa, mas a que descreve a realidade, com suas dores e cores, fornecendo a visão de um país diversificado - no tempo e no espaço. Sob esta ótica, a consciência nacional deveria não só admirar a "virtude do espontâneo", mas se ater aos problemas do Brasil.

\section{O ESTADO COMO NAÇÃO}

Podemos observar, conforme indicado por diversos autores (Alencastro 1989; Carvalho 1996; Faoro1975; Oliveira 1990) que o processo de construção do Estado, no caso brasileiro, se antecipou, em muito, ao da construção da nação. Esta vem a se tornar uma preocupação no final da Primeira República, e efetivamente, um desafio para a geração pós-30. O surgimento da "nação" vincula-se às transformações por que passa a 
sociedade européia nos séculos XVII e XVIII: a consolidação do Estado moderno e simultaneamente a instauração do individualismo enquanto ideologia hegemônica. A nação realiza no coletivo a moderna concepção de indivíduo, qualificando-se analogamente com atributos; ou seja, espera-se que toda coletividade tenha caráter, personalidade, autonomia, vontade, memória. Este processo de auto-definição tem como contexto a realidade inter-nacional, que envolve relações de poder e competição. Claro está que este intuito de busca de origens é principalmente um exercício de resgate e reconstrução - nos termos de Hobsbawn \& Ranger (1989), de invenção de tradições - que ocorre num momento de crescente industrialização, e na moderna confiança, senão crença, no progresso, na ciência, na tecnologia. Peter Burke (1989) narra quão surpresos ficaram aqueles camponeses europeus quando, em pleno século XVIII, viram suas casas invadidas por senhores distintamente vestidos, de palavras difíceis, pedindo-Ihes que cantassem ou narrassem histórias que ouviram na infância. Para os intelectuais, o povo era um mistério, que passou a ser descrito e valorizado exatamente nos termos de tudo que eles não eram. A influência da filosofia romântica se entrevê nesta busca da essência das coletividades, valorizando-se a pureza das criações coletivas.

No processo de dotação de atributos a coletividades políticas, ocupa grande peso a caracterização da natureza de "seu" território, no intuito de nacionalizá-lo. A busca pela expressão da essência estimula a perspectiva de se vincular, originalmente, o território com sua população.

O nacionalismo brasileiro vem marcado por uma forte ênfase na auto-estima coletiva e na afirmação do próprio contra o imposto, numa atitude compensatória à sua posição periférica. Como parte do Novo Mundo, a realidade é marcada, desde sua instauração, pelo domínio do espaço geográfico, definido como processo básico de formação do Estado. A ausência de um passado histórico remoto, como no caso europeu, revelase como fator marcante para o processo básico de formação do Estado (Oliveira 1998). A debilidade da tradição é compensada pela exuberância do espaço: clima, rios, fauna, flora. A ideologia nacional do espaço territorial teve grande êxito e mostrou-se eficaz como fornecedora de um sentimento de pertencimento. Nesta construção do espaço se entrevê uma polaridade básica na qual o território é percebido primordialmente pela diferença entre litoral e interior, o sertão. Se no período colonial predomina a conquista do sertão hostil, que deve ser vencido, na Primeira República verifica-se a positivação do "interior", locus da cultura rural e da nacionalidade autêntica. Na verdade, a transformação de "Os Sertões" de Euclides da Cunha em monumento nacional (Abreu 1998) é sinal significativo de mudança de valores na sociedade brasileira; e o sertão vai se debulhando em regiões, ou diferentes sertões. Em oposição à contaminação e descaracterização do litoral, reina a imensidão desconhecida, reservatório da pureza intacta. Contudo, não basta simplesmente reconhecer o sertão, é preciso enfrentá-lo como problema. Urge então uma ação sistemática para torná-lo efetivamente 
território nacional. O depoimento de Euclides da Cunha é um alerta à distância temporal do sertão , que colocaria em risco o próprio projeto nacional. Esta percepção, de fato não é nenhuma novidade, pois é partilhada por diversos intelectuais ao longo da história brasileira, dentre estes, os próprios literatos. No período imperial temos como exemplo o depoimento de Domingos Gonçalves de Magalhães que narra a situação de choque cultural ocorrido na Balaiada, revolta popular na Província do Maranhão: Estrangeiras são nossas instituições, inconciliáveis as diferenças de classes. Os cafusos do interior distinguem-se apenas dos selvagens pelo uso da língua...." (Alencastro 1989: 12).

O movimento folclórico, resultado do engajamento de um número expressivo de intelectuais na valorização da cultura popular e que movimentou a cena nacional na primeira metade do século passado, contribui, mais ainda que os integrantes do Movimento Modernista, para o reconhecimento da diversidade regional. Através da investigação sistemática de aspectos variados da cultura popular, inclusive hábitos alimentares, buscam as raízes autênticas deste povo, seja na transmissão oral, seja na vida comunitária de grupos que se beneficiam do isolamento dos grandes centros. A partir de um certo "colecionismo descontrolado" (Vilhena 1997) tem a peculiaridade, enquanto movimento, de atrair os intelectuais "de província", ou seja, representantes de grupos regionais muitas vezes marginalizados no grupo hegemônico. Neste exercício de reinvenção do Brasil, destacase a consideração da cultura popular como patrimônio regional. Neste sentido, as regiões passam a ser interessantes por si próprias, uma vez que o que se enfatiza é justamente o destaque regional na nação unificada.

\section{DAS DESCONTINUIDADES ALIMENTARES}

O estudo da alimentação tem local privilegiado na análise cultural. Através da discrição da prática cotidiana, desenrola-se esta atividade indispensável à sobrevivência humana. Contudo, a complexidade dos códigos alimentares não se reduz à satisfação de necessidades fisiológicas. A partir de um sistema particularmente elaborado sobre o comestível, ou o tóxico, temos acesso à um tipo de ordenação social e cosmológica: definir os alimentos comestíveis, a forma de prepará-los, combiná-los, assim como as situações de utilizá-los, com quem repartir. Os hábitos alimentares nos permitem conhecer uma sociedade; falar de cozinha não se limita a falar de prazeres gustativos, mas fundamentalmente de princípios simbólicos.

A ordem cultural é construída em termos de uma coerência de um mundo diferenciado e unificado; a ordem alimentar, um dos níveis onde se exprime simbolicamente a representação do mundo. Lévi-Strauss 
(1964) é um dos autores que mais enfatizou o espaço da cozinha como cenário privilegiado de reprodução das classificações culturais de uma sociedade. Aliás, a partir de uma perspectiva universalista focaliza-a como experiência humanizadora, presente em todas as culturas. Assim como não existe sociedade humana sem língua falada, não existe sociedade que, de um modo ou de outro, não processe seu alimento. Lévi-Strauss acredita ser a culinária esfera privilegiada de acesso à cultura, na medida em que revela o uso social dos alimentos, domínio do reino natural. A forma como se apreende e se relaciona com a natureza, a qualidade das classificações que se utiliza e o modo como são manipuladas são instâncias definidoras da singularidade cultural. É neste sentido que a cozinha de uma sociedade revela-se como eixo central da integração entre Natureza e Cultura. O acesso aos alimentos, sua in-corporação, será sempre mediada pela forma cultural. Edmund Leach (1983) vem contribuir com esta reflexão, ao analisar a forma culturalmente construída de distinções entre animais comestíveis e não comestíveis - domésticos, semi-domésticos e estranhos - a partir do critério de proximidade e distância em relação ao grupo social, o que vai ser simbolizado na forma de tabus alimentares.

Contudo a pluralidade de formas alimentares não se restringe a diferentes culturas, mas se faz presente dentro da mesma sociedade. Em particular, as sociedades complexas têm se revelado como campo fértil de análise da íntima relação existente entre as regras de comestibilidade e as regras de conduta social. Bourdieu (1979) analisa as estratégias de aspiração social traçadas pelas classes componentes da sociedade francesa, onde o consumo alimentar, dentre outros aspectos, opera como elemento distintivo; as preferências alimentares, refletindo o universo simbólico daqueles que as partilham, traduzem, mas principalmente reforçam, o status daquele grupo, sua localização, não só dentro da sociedade, como dentro de uma mesma classe social. Sahlins (1979), por sua vez, analisa o comportamento alimentar da sociedade norte-americana, cujos hábitos alimentares são orientados sobretudo por uma lógica cultural, onde as regras econômicas e racionais do mercado , tais como escassez e abundância, pouco atuam na definição de alimentos mais ou menos valorizados. De forma diferenciada, estes autores procuram explicar a distribuição contemporânea de preferências alimentares através do processo social de exclusão.

As preferências alimentares figuram entre traços distintivos e singularizantes; e não só variam entre sociedades, grupos sociais, como podem se diferenciar internamente a estes grupos, como comida de homem e de mulher, de criança e de adulto, de homens e de deuses. Revela-se como campo fértil de investigação cultural a observação do modo pelo qual a alimentação participa das intenções sociais e morais dos indivíduos; a focalização da comida como campo de ação, um meio através do qual outros níveis de categorização social 
se manifestam. Assim a continuidade de hábitos alimentares, a manutenção de uma certa tradição é resultado da manipulação de um repertório de formas constantemente negociado entre os atores sociais. A cozinha étnica, por exemplo, antes que um conjunto de receitas, é muito mais uma categoria cultural; ela persiste onde o sentimento de distinção é valorizado, onde há um sentido mais amplo para ser vivenciada. Em geral, os hábitos alimentares de grupos etnicamente distintos se diluem nos padrões alimentares mais amplos na medida em que outras fronteiras culturais se apagam.

Comer e beber são fatos socioculturais que variam segundo o tempo e o espaço. Seja o tempo, o processo histórico ou o ritmo das estações; seja o espaço, os grupos sociais distintos dentro de uma mesma sociedade, as nações ou as regiões.

Grande parte da história brasileira pode ser narrada pelo esforço do poder centralizador em converter as regiões em parte da nação, tanto em termos econômicos e administrativos, quanto políticos e simbólicos. As estradas de ferro, o serviço militar obrigatório, o fortalecimento do mercado interno são fatores que contribuíram para esta integração, juntamente com seus heróis, como o Marechal Rondon.

Para além de algumas fórmulas nacionalizadas, como o samba ou a umbanda - as raízes do sentimento nacional ancoram-se na configuração única de partes diversas. A diversidade ambiental reproduz-se na diversidade regional, que se torna desta forma, patrimônio nacional. Pois além da definição de fronteiras territoriais e culturais contínuas é preciso que a nação possua bens culturais.

Entre os atributos da nação brasileira que pontuam a eternidade do solo, figuram as fontes alimentares. Que não se esqueça a dimensão histórica na composição das cozinhas regionais, o intercâmbio de culturas ao longo do tempo. Mas também que não subestimemos as particularidades estimuladas pelo ambiente. No caso brasileiro, dada a carga simbólica conferida à dimensão espacial, "a natureza é nossa riqueza”, incluindo-se aí a profusão tropical alimentar. Mais que simplesmente a diferença, a construção das cozinhas regionais, com seus pratos emblemáticos e combinações singulares marcam a consciência da originalidade.

"Regio" origem etmológica latina de região, ressalta em seu significado o ato de delimitar. Uma divisão mais ou menos fundada na realidade, pois instaura-se uma descontinuidade decisória na continuidade natural. É importante destacar que por detrás da identidade regional jaz a construção de uma fronteira. Funda-se em propriedades ligadas à origem, portando marcas duráveis. São resultado de lutas de classificação, para se impor a divisão do mundo social pelo monopólio "de poder fazer ver e fazer crer" (Bourdieu 1980). O discurso regionalista é um discurso performativo cuja autoridade de definição de critérios depende do reconhecimento e da crença de seus membros nas propriedades culturais que possuem. 
Julia Csergo (1998) nos relata o florescimento das cozinhas regionais na França como resultado de fenômenos que se intercruzam. Primeiro, a preocupação com a "questão nacional" das autoridades francesas após a Revolução, quando buscava-se a fundação da nação histórica pela composição do diverso. Segundo, pelo desenvolvimento dos meios de transporte, que permitiu a maior número de pessoas o acesso ao território francês. Além destes fatores, o grande êxodo para os grandes centros, formadores do mercado consumidor, favorece a ploriferação de restaurantes regionais nas metrópoles. Por sua função memorial, as cozinhas regionais possibilitam ao "estrangeiro" o acesso à modalidade de percepção de uma região, aguçando uma sensibilidade particular.

Vale ainda destacar a contribuição de Jeffrey Pilcher (1998), que, através dos hábitos alimentares narra a história do México e todo o processo de conflitos e negociações, entre parcelas distintas da população, e de regiões, que envolveu a construção de sua identidade nacional. Apesar de grandes variações regionais, a integração interna ocorrida no país - seja comercial, viária ou política - ao longo dos séculos XIX e XX foi determinante para a consolidação da "Cozinha Mexicana".

As cozinhas regionais não se reduzem a uma lista de receitas diferentes. Envolve ingredientes, métodos culinários, pratos, formas de sociabilidade e sistema de significados. Ancora-se na experiência vivida, o que a torna de difícil percepção por parte dos próprios atores; a naturalização dos hábitos alimentares traz marca profunda por sua função constitutiva no processo de socialização. O sentido destas práticas, sua vinculação ao "pertencimento" ao grupo, são fruto de reconstruções e negociações que se fazem no presente; nem sempre o típico, o emblemático é o cotidiano, apesar de ser representado como "característico".

Gilberto Freyre (1968) e Luís da Câmara Cascudo (1983) são autores que se ressaltam pelo destaque que dedicam à questão alimentar como fator constitutivo da identidade nacional. Podemos considerá-los portadores, dentre outros, do projeto da inteligentsia brasileira, na primeira metade do século passado, de construir a identidade nacional valorizando o espaço regional, e o que era considerado como grande empecilho para nossa construção como nação e para o "progresso" da sociedade brasileira: a mistura, a mestiçagem que nos distanciava do padrão europeu de tradição mas conferia grande riqueza à culinária brasileira.

As terras brasileiras atuam como cenário, na perspectiva destes autores, em que se assiste o contato de três culturas diferentes, a ameríndia, a africana e a portuguesa, destacando as possibilidades de enriquecimento cultural que se deu pela via do "empréstimo" e do "acréscimo". A confraternização da cultura na culinária resulta na diversidade de ingredientes, temperos, combinações; que se mantêm vivas, seja pelas receitas, pelas nominações, pelas ocasiões de uso. Gilberto Freyre, em 1926, lança em Recife, o Manifesto Regionalista, 
onde defende a região como base de organização nacional e a conservação dos valores regionais (leia-se tradicionais) do Brasil. É um movimento que se apresenta significativamente como um "grupo apolítico de 'Regionalistas' [que] se reúne em volta da mesa do chá com sequilhos e doces tradicionais da região (...) preparados por mãos de sinhás" (Oliven 1986:70). Trata-se de um autor que inovou a análise da cultura brasileira por valorizar dimensões pouco reconhecidas, como os bastidores do cotidiano, entre eles os hábitos alimentares e as relações sociais neles envolvidas. No seus termos, preocupações aparentemente "femininas em torno de assuntos docemente inofensivos" (op. cit.: LXX). Vale ainda destacar o livro Açúcar (1997) onde focaliza o doce como categoria cultural significativa da cultura brasileira, e em especial do Nordeste . Tanto Freyre como Cascudo merecem especial destaque na investigação das gramáticas culinárias brasileiras, e em especial das práticas tradicionais. A ênfase na autenticidade, a busca de raízes, faz transparecer uma certa nostalgia quanto à originalidade do passado, um tanto quanto agreste e tradicional, em processo de descaracterização frente ao progresso e à urbanização. Ressaltam a cozinha como patrimônio cultural a ser valorizado, uma arte coletiva, sem heróis individuais, que surge espontaneamente, como árvores na natureza.

A modernidade conduziu-nos, no processo de construção da nação, à consciência de uma especificidade regional. Frente à padronização das sociedades industriais, à provisoriedade das formas, o discurso regionalista vem fundar a legitimidade na tradição. Está ligado às origens, ao lugar e às marcas duráveis, dando uma definição legítima do mundo social. A culinária, como já foi mencionado, é um dos vetores freqüentemente utilizados na vivência deste referencial identitário. Delimitar uma cozinha envolve variados aspectos. Apesar de muitas vezes ancorar-se na delimitação geográfica, sua extensão é definida socialmente. Numa certa dimensão, as cozinhas regionais apresentam-se como resultado de combinações singulares entre condições históricas e espaciais; contudo, é a associação simbólica ao significado de certas práticas para a constituição de certa identidade, e não sua "autenticidade histórica", que as fundamenta. Como exemplo ilustrativo deste fato, pode-se destacar o artigo "Cozinha Mineira, Patrimônio Paulista" (Maranhão 2003), onde o autor apresenta o argumento de que a cozinha mineira, apesar do discurso singularizante, é originalmente paulista; chegou à Minas juntamente com os bandeirantes no período colonial, demonstrando que são conhecidos como "mineiros", "pratos corriqueiros no Centro e no Sudeste do Brasil" (p.86).

Contudo, apesar de todo este trabalho de construção simbólica, pode-se dizer, juntamente com Mintz (1996), que as "comidas" de um país são, antes que nacionais, regionais. As cozinhas ancoram-se num lugar, onde se tem alguma referência de pessoas utilizando-se de ingredientes, métodos, receitas numa base regular de produtos. Neste processo de tipificação das cozinhas regionais, alguns pratos se tornam especialmente 
representativos, marcas de orgulho e distinção. Assim, o quadro de diversidade territorial e cultural brasileiro apresenta pratos típicos conforme as regiões: "Arroz com Pequi", de Goiás; "Tutu com Lingüiça”, de Minas; "Churrasco Gaúcho; "Tacacá e Tucupi" da região norte; "Baião de Dois", do Ceará; "Acarajé e Vatapá", da Bahia (Maciel 1996).

Nesta combinação de qualidades singulares, observa-se que a composição de atributos alocados a cada região (e a seu habitante) é resultado de múltiplas variáveis. Algumas, podemos identificar, outras fogem à simples relações causais, fruto que são da interconexão de diversos fatores, sejam eles históricos, ecológicos, econômicos ou que se enquadram ao espaço mágico que a antropologia construiu sob o signo de "arbitrário". Os estados constroem de forma diferenciada sua teia identitária. A identidade paulista, por exemplo, ancorase fortemente na figura do bandeirante desbravador que se fez herói da unidade nacional. A culinária regional, desta forma, se destaca mais em algumas situações do que em outras. Pretendo refletir sobre três situações em particular, que por motivos diversos, têm a "cozinha" como traço marcante na construção da identidade regional. Naturalmente, existem outros exemplos possíveis, mas estes se apresentam particularmente emblemáticos para esta reflexão.

A "Cozinha Gaúcha", como ocorre freqüentemente nas cozinhas regionais, se constrói através de tipificações, da eleição de determinadas composições culinárias como marcas exteriores de distinção. Apesar da riqueza de sua culinária, com grande variedade de combinações, os gaúchos são conhecidos e reconhecidos pelo Brasil afora pela preferência ao chimarrão como bebida habitual e a prática de fazer churrascos. Não é qualquer churrasco, mas o "Churrasco Gaúcho" que tem formas características de se preparar e de se servir, como por exemplo, ser somente temperado com sal grosso. (Maciel 1996) O churrasco autêntico exige a competência de um gaúcho autêntico em seu preparo, aquele que domina um saber apreendido pela tradição. À competência da "arte de fazer churrasco" complementa-se a autoridade de julgá-lo, se original ou não; o que cabe certamente, ambas as funções, a um nativo. A notoriedade do churrasco, fortemente emblemático, associa-se a diversos fatores possíveis. Sua popularização certamente associa-se ao tipo de sociabilidade que o envolve, seu caráter mais festivo e informal. A própria densidade simbólica que envolve a carne enquanto alimento em nossa cultura ocidental, reforça a imagem de abundância e fartura, onde é qualificada como "o verdadeiro alimento". A identidade gaúcha apóia-se na composição singular entre a história desta região e sua dimensão espacial. Ancora-se na construção do "gaúcho", um tipo social bem definido, que por seus caracteres aproxima-se mais de seu homônimo no Uruguai ou Argentina, do que do resto do Brasil.(Oliven 1984).Como habitante dos pampas, tem a vida livre percorrendo vastos campos à cavalo, o que lhe conferiria grande 
bravura. O clima de adversidades a que é submetido este personagem qualifica sua virilidade; seja a hostilidade da vida campeira, seja a dura realidade de fronteira, sujeita a constantes conflitos. Ao longo da história, o Rio Grande do Sul relacionou-se com o território brasileiro de forma ambígua, revelando uma tensão entre autonomia - a possibilidade de se separar do Brasil - e integração, entre manter sua peculiaridade e afirmar seu pertencimento. Pois neste passado de vida campeira, movida pelo comércio de couro é que aloca-se o hábito de se comer carne assada ao calor de brasas. Churrasquear não é simplesmente comer churrasco, mas implica uma série de relações sociais que o viabiliza, como quem prepara, quem come, neste ritual de comensalidade e partilha. Envolve relações de gênero bem definidas; ao contrário da divisão social do trabalho mais freqüente, que reserva este espaço da preparação do alimento ao universo feminino, no mundo do churrasco, cabe aos homens sua preparação, uma atividade que se aprende e se ensina no processo de socialização.

A Cozinha Baiana é testemunho da continuidade territorial entre os extremos leste e oeste do Atlântico Sul, do estreito vínculo entre a costa africana e o Brasil durante quase trezentos anos. Como porto expressivo do comércio negreiro, Salvador assiste ao constante ir e vir de gentes, modas, crenças religiosas, alimentos e receitas. Espetáculo freqüente nos mercados, na rua, aqui e lá, as túnicas multicores, as vendedoras de quitutes; as baianas se delineiam como o tipo social característico desta cozinha, capaz de sintetizar sua essência. É uma cozinha em que se destacam o exotismo dos nomes, o inusitado das combinações, o calor do tempero e a natureza tropical de seus ingredientes. Exuberante e afrodisíaca em função dos estimulantes do paladar. A partir do uso do azeite de dendê desfilam frutos do mar, peixes, camarões secos, "matos" daqui e acolá, milhos, feijões, mandioca, arroz e coco. Os portugueses enriqueceram a flora africana com um conjunto de plantas, como o milho e a mandioca; os africanos trouxeram consigo inumeráveis outras. Semelhantes são as técnicas de preparação nas costas brasileira e africana, porém, se a cozinha na costa leste do Atlântico manteve-se mais etnicamente definida, distinta da portuguesa; aqui, revela-se mais sincrética com a introdução de novos aromas e sabores. Contudo, de forma mais sutil que em outras partes do Brasil. $\mathrm{O}$ caráter religioso da cozinha baiana contribuiu para que ainda permaneça tão localizada e pouco alterada ao longo do tempo: cada deus tem seu prato preferido, permanecendo assim, esta cozinha, vinculada ao mundo dos orixás. Como bem se refere Bastide (1970), os deuses não mudam facilmente de costume.

É de Drummond (Sabino 1991) a observação de que as pessoas falam do mineiro como se este fosse o único a ter peculiaridades da região de origem, o que aconteceria com o nascido em qualquer outro estado. Mas, ele mesmo, entre tantos outros escritores mineiros, delineia Minas Gerais com palavras que identificam 
a existência de um "mistério" que envolve a região. Enfatizam a qualidade desta definir-se pelo conteúdo, ou nos termos de João Guimarães Rosa (1985) de ser "Brasil em ponto de dentro". O mineiro muitas vezes é reconhecido por características tais como sobriedade, honestidade, modéstia, religiosidade. Sua vida social estaria condicionada pela cadeia de montanhas, pela autonomia das fazendas, gerando um espaço propício à estabilidade social, à sedentariedade e ao mundo das relações imediatas. A cozinha mineira, como seu personagem, é qualificada como simples, mas substancial. Baseando-se na versatilidade do uso do milho, no feijão, hortaliças silvestres e a preferência pela carne suína, é enriquecida com grande variedade de doces. Resultado de uma cultura agrária, revela-nos um sincretismo silencioso que se molda ao longo do tempo. Se singulariza pela trivialidade; seu protagonista, antes que um personagem, é a "família tradicional" e religiosa. Cenário principal da vida cotidiana doméstica, a cozinha mineira acontece na intimidade do mundo da casa e das relações pessoais, ao contrário do ar livre do churrasco dos pampas ou do mundo público, festivo, dos mercados dos quitutes baianos. Não deve faltar entre seus ingredientes o fogão de lenha, a velha cozinheira negra, a supervisão materna, o tempero de alho e cebola, o café, as quitandas, o queijo "mineiro", a boa conversa. Na perspectiva de Alceu Amoroso Lima (1945), Minas seria a "Voz do Centro", por se caracterizar pela compensação, equilíbrio, moderação. A cozinha mineira define seu espaço, no leque das diversas regiões, não pelo exotismo ou pela situação longínqua de fronteira, mas como síntese; por sua trivialidade, síntese da cozinha ordinária.

A questão da culinária regional envolve considerações diversas; supõe a existência de certa homogeneidade em determinado território, seja de padrões alimentares, seja de representações sociais. É possível que se identifique semelhanças, aproximações entre duas cozinhas, mas sempre haverá marcos diferenciais, que por pequenos que sejam, definem fronteiras. Vale ressaltar, no entanto, que a distribuição de hábitos alimentares obedece a lógicas distintas à divisão política do território entre estados, ocorrendo diferenças entre padrões alimentares dentro de um mesmo estado, ou semelhanças entre outros.

A construção da singularidade regional é testemunho da importância crucial do projeto de auto-definição para a convivência federativa no seio da unidade nacional. Envolve questões que, de acordo com Oliven (1986) se fazem recorrentes em nossa história na formulação de modelos para organizar a nação: a decisão entre unidade e diversidade, nacional e estrangeiro, popular e erudito, tradição e modernidade, nação e região. $\mathrm{O}$ que não implica necessariamente na escolha entre polaridades, mas se apresenta como resultado de composições, em que estes aspectos se fazem simultaneamente presentes. 
Assim como outras expressões da vida social, os hábitos alimentares também podem ser tomados como operadores de distinções, demarcam fronteiras impondo uma divisão legítima do mundo social Apresentamse como textos que narram a história de constituição de um grupo, sua contextualização presente, traduzindo, simultaneamente o código de valores que orientam a prática social. Por sua contribuição ao processo de singularização cultural, eles participam da própria representação que o grupo faz de si, da constituição de sua identidade.

Se o movimento folclórico teve grande contribuição na ênfase regional, valorizando-se bens culturais até então desconhecidos como patrimônio da nação, a partir da década de 50, o nacionalismo brasileiro, na figura de seus intelectuais, assiste a uma mudança radical. No lugar do discurso ufanista e saudoso, a consciência do atraso, a noção de subdesenvolvimento. O que se torna mais importante para a "conscientização" de um país subdesenvolvido, como o Brasil, não é mais sua "riqueza", mas sua desigualdade. O discurso da riqueza da diversidade regional vai lentamente se deslocando da reflexão social para o empreendimento turístico, onde certamente as cozinhas regionais ocupam papel de destaque. Na verdade, o esgotamento do discurso nacionalista que assistimos desde então reflete a ausência reiterante de seu par complementar, que é a experiência de cidadania. Talvez seja um bom caminho para pensarmos que, ao contrário de receitas tradicionais, pratos emblemáticos, práticas artesanais, a tônica nacional do presente se traduza no projeto de erradicação da fome. Que não é problema simplesmente econômico, como muitas vezes parece, mas social, como já dizia Josué de Castro (2001), onde a sociedade brasileira se revela no dilema entre "o pão e o aço". Em outras palavras, torna-se desafio construir um projeto nacional mais unificado e menos centralizador. 


\section{REFERÊNCIAS BIBLIOGRÁFICAS}

ABREU, Regina. 1998. O Enigma dos Sertões. Rio de Janeiro: Funarte/Rocco.

ALENCASTRO, Luis Felipe. 1987. “A Pré-Revolução de 30" Novos Estudos Cebrap. 18.

. 1987."O Fardo dos Bacharéis" .Novos Estudos Cebrap. 19.

1989. “Memórias da Balaiada". Novos Estudos Cebrap. 23.

2000. O Trato dos Viventes: formação do Brasil no Atlântico Sul. São Paulo: Companhia das Letras.

BASTIDE, Roger. 1970. El Projimo y el Extraño. El Encuentro de las Civilizaciones. Buenos Aires: Amorrortu Editores.

BOURDIEU, Pierre. 1979. La Distinction: Critique Sociale du Jugemente. Paris: Ed. Minuit.

. 1980. "L'identité et la representation: elements pour une reflection critique sur la idée de region." Actes de la Recherche en Sciences Sociales. 35.

BURKE, Peter.1989. A Cultura Popular na Idade Moderna. Europa 1500-1800. São Paulo: Companhia das Letras.

CÂNDIDO, Antonio. 1984. "A Revolução de 30 e a Cultura”. Novos Estudos Cebrap. 2.

CARVALHO, JOSÉ Murilo de. 1990. A Formação das Almas. O Imaginário da República no Brasil. São Paulo: Companhia das Letras.

1996. A Construção da Ordem: A Elite Política Imperial. Teatro de Sombras: A Política Imperial. Rio de Janeiro: UFRJ/ Relume Dumará.

CASCUDO, Luís da Câmara.1983. História da Alimentação no Brasil. São Paulo/ Belo Horizonte: Editora USP/Itatiaia.

CASTRO, Josué de. 2001. Geografia da Fome. Rio de Janeiro: Civilização Brasileira.

CSERGO, Julia. 1998."A emergência das cozinhas regionais". In: FLANDRIN, Jean-Louis \& MONTANARI, Massimo. História da Alimentação. São Paulo: Estação Liberdade.

DUTRA, Rogéria Campos A. 1991. A Boa Mesa Mineira. Um estudo de cozinha e identidade. Universidade Federal do Rio de Janeiro/Museu Nacional/PPGAS. Dissertação de Mestrado.

ELIAS, Norbert. 1993. O Processo Civilizador. Formação do Estado e Civilização.v.2 Rio de Janeiro: Jorge Zahar.

FAORO, Raimundo. 1975. Os Donos do Poder: Formação do Patronato Brasileiro. Porto Alegre: Globo São Paulo: Cia Editora Nacional

FREYRE, Gilberto. 1968. Sobrados e Mucambos. Decadência do Patriarcado Rural e Desenvolvimento do Urbano. Rio de Janeiro: José Olympio.

1997. Açúcar. Uma Sociologia do Doce, com receitas de bolos e doces do Nordeste do Brasil. São Paulo, Companhia das Letras.

FRY, Peter. Para Inglês Ver: Identidade e Política na Cultura Brasileira. Rio de Janeiro: Zahar.

GONÇALVES, José Reginaldo. 1988."Autenticidade, Memória e Ideologias Nacionais" Estudos Históricos . Rio de Janeiro v.1,n.2. 

Funarte.

2002. "A Fome e o Paladar: Uma Perspectiva Antropológica." Seminário Alimentação e Cultura Rio de Janeiro:

HOBSBAWN, Eric \& Ranger, T. (org.).1984. A Invenção das Tradições. Rio de Janeiro: Paz e Terra.

LEACH, Edmund. 1983. "Aspectos Antropológicos da Linguagem: Categorias Animais e Insultos Verbais" In: DA MATTA, Roberto (org.). Edmund Leach. São Paulo: Ática. (Coleção Grandes Cientistas Sociais).

LÉVI-STRAUSS, Claude. 1964. Le Cru et le Cuit. Paris: Plon.

LIMA, Alceu Amoroso. 1945. Voz de Minas. Ensaio de Sociologia Regional Brasileira. Rio de Janeiro: Agir Editora.

MACIEL, Maria Eunice. 1996. “Churrasco à Gaúcha”. Horizontes Antropológicos. Ano 2, n.4

MARANHÃO, Ricardo. 2003. "Cozinha Mineira, Patrimônio Paulista". Revista História Viva. São Paulo: Duetto Editorial. Nov., ano1, n. 1.

MAUSS, Marcel. 1972. “La Nación”. In: Sociedad y Ciencias Sociales. Obras II. Barcelona: Barral Editores.

MINTZ, Sidney. 1996. Tasting Food, Tasting Freedom. Boston: Beacon Press.

OLIVEIRA, Lucia Lippi. 1990. “Modernidade e Questão Nacional” Lua Nova. Revista de Cultura e Política. n.20.

vol.5. . 1998. "A Conquista do Espaço: Sertão e Fronteira no Pensamento Brasileiro". História. Ciências Sociais. Saúde.

OLIVEN, Ruben George. 1984. "A Fabricação do Gaúcho". Ciências Sociais Hoje. Anuário de Antropologia, Política e Sociologia. São Paulo.

OLIVEN, Ruben George. 1986."O Nacional e o regional na construção da identidade brasileira". Revista Brasileira de Ciências Sociais. n.2, v.1.

. 1988. “A Atualidade da Questão Regional". Revista Brasileira de Ciências Sociais. v.2 (1). . 1989. “O Rio Grande do Sul e o Brasil: uma relação controvertida". Revista Brasileira de Ciências Sociais. n.9,v.3.

PILCHER, Jeffrey.1998. Que vivam los Tamales! Food and the Making of Mexican Identity. Albuquerque: University of New Mexico Press.

REIS, Elisa P. “O Estado Nacional como Ideologia: O Caso Brasileiro.” Estudos Históricos vol.1, n.2.

ROSA, João Guimarães.1985. “Minas Gerais”. Ave, Palavra. Rio de Janeiro: Nova Fronteira.

SABINO, Fernando.1991. “Mineiridade: vamos mudar de assunto”. Revista Veja. São Paulo: Ed. Abril, n.17, 24/04/1991.

SAHLINS, Marshall.1979. Cultura e Razão Prática. Rio de Janeiro: Zahar.

VELLOSO, Monica P. 1988. "A Literatura como Espelho da Nação". Estudos Históricos vol.1, n.2.

VIANNA, Hermano. 1995. O Mistério do Samba Rio de Janeiro: Zahar/UFRJ.

VILHENA, Luis Rodolfo. 1997. Projeto e Missão. O Movimento Folclórico Brasileiro.1947-1964. Rio de Janeiro: Funarte/ Fundação Getúlio Vargas. 
Nação, região, cidadania: a construção das cozinhas regionais no projeto nacional brasileiro RES U M 0

A proposta deste artigo é analisar o papel das cozinhas regionais na formação da nação brasileira. O processo histórico de construção da identidade nacional fundamenta-se na conciliação entre a unidade territorial e a diversidade regional, onde as cozinhas regionais atuam como operadores distintivos que qualificam a riqueza nacional.

PALAVRAS-CHAVE: identidade nacional, cozinha regional, hábitos alimentares

Nation, region, citizenship: the construction of regional cuisines in the Brazilian national project ABSTRACT

This article investigates the role of regional cuisines in the building process of Brazilian national identity. Historically, this process has been based on the conjunction of territorial unity and regional diversity, in which regional cuisines act as hallmarks of national wealth.

KEY WORDS: national identity, regional cuisine, food habits 